Springer Japan KK 
Yoshitaka Okada

\section{Competitive-cum-Cooperative Interfirm Relations and Dynamics in the Japanese Semiconductor Industry}


OKaDA Yoshitaka

Professor of Sociology and Business

Faculty of Comparative Culture, Sophia University

4 Yonban-cho, Chiyoda-ku, Tokyo 102-0081, Japan

ISBN 978-4-431-67984-4

Library of Congress Cataloging-in-Publication Data

Okada, Yoshitaka, 1949-

Competitive-cum-cooperative interfirm relations and dynamics in the Japanese semiconductor industry / Yoshitaka Okada.

p. $\mathrm{cm}$.

Includes bibliographical references and index.

ISBN 978-4-431-67984-4 ISBN 978-4-431-67923-3 (eBook)

DOI 10.1007/978-4-431-67923-3

1. Semiconductor industry-Japan. 2. Integrated circuits

industry-Japan. 3. Strategic alliances (Business)-Japan.

4. Interorganizational relations-Japan. 5. Competition-Japan.

I. Title.

HD9696.S43J354 2000

$338.4^{\prime} 762138152^{\prime} 0952-\mathrm{dc21} \quad 99-41456$

Printed on acid-free paper

(c) Springer Japan 2000

Originally published by Springer-Verlag Tokyo in 2000

Softcover reprint of the hardcover 1st edition 2000

This work is subject to copyright. All rights are reserved, whether the whole or part of the material is concerned, specifically the rights of translation, reprinting, reuse of illustrations, recitation, broadcasting, reproduction on microfilms or in other ways, and storage in data banks.

The use of registered names, trademarks, etc. in this publication does not imply, even in the absence of a specific statement, that such names are exempt from the relevant protective laws and regulations and therefore free for general use. 


\section{Table of Contents}

List of Tables $\quad \mathrm{xi}$

List of Figures $\quad x v$

Preface xvii

Introduction 1

\section{Chapter One \\ Theory of Competitive-cum-cooperative (CCC) Interfirm Governance 15}

A. Theoretical Bases: Transaction Cost Economics and Path-dependent Institutional Development

B. Harmonizing Mechanisms and Path-dependent Institutional

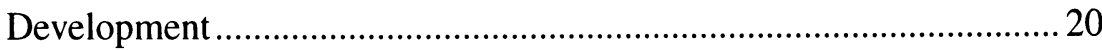

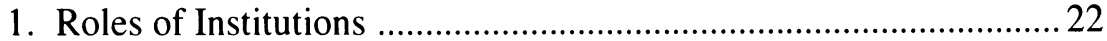

2. Types of Intra- and Interfirm Interaction and Governance ............. 23

C. Institutions and Transformation of Cooperative Behavior .................... 26

1. Traditional and Rigid Cooperation ................................................. 26

2. Transformation to Flexible Cooperation .......................................... 30

D. Competitive-cum-cooperative Interfirm Relations ................................33 
1. Cooperation-promoting and Competition-generating Measures .... 34

2. Flexible-synergy and Market-like Effects .......................................... 36

3. Logic of Continuity ........................................................................ 36

4. Power Relationships and Logic of Continuity .................................. 38

5. Cooperation- and Competition-oriented CCC Interaction (Influence of Market Conditions and Functions) ............................ 41

6. Measures Generating Flexible-synergy and Market-like Effects .... 44

E. Propositions for Empirical Inquiry ...................................................5 50

\section{Chapter Two Technological Development, Corporate Strategies and Market Competition 53}

A. Typology of Technological Innovativeness ..........................................5 54

B. Development of the Transistor in Japan ..............................................59

1. Experimental Imitation Period (1948 - 1953) ................................... 59

2. Imitation-for-production Period (1954 - 1959) .................................. 61

3. Innovative Imitation Period (1960 - 1964) ...................................... 63

C. Development of the Integrated Circuit (IC) and Other

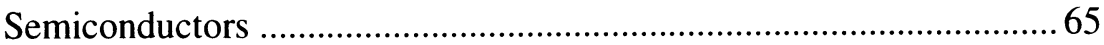

1. Experimental Imitation Period (1958 - 1962) ...................................6 65

2. Market Uncertainty Period (1963 - 1964) ......................................... 66

3. Innovative Imitation Period (1965 - 1967) .......................................67 67

4. Application Engineering Period (1968) ............................................ 68

D. Development of the Large-scale Integrated Circuit (LSI) and Other Semiconductors

1. Application Engineering Period with Market Uncertainty (1969 - 1971)

2. Application Engineering Period (1972 - 1974) . 
E. Development of the Very-large-scale Integrated Circuit (VLSI) and Other Semiconductors - Leveraged Creativity Period (1975 - 1983) 73

F. Development of Ultra-large-scale Integrated Circuit (ULSI) and Other Semiconductors - Leveraged Creativity Period (1984 - 1992) 78

\section{Chapter Three Basic Characteristics of Intra- and Interfirm Interaction 85}

A. Prevalence of Competitive-cum-cooperative Interaction in Business Transactions 86

B. Nature and Characteristics of Interaction 89

1. Procurement of Parts and Materials .................................................. 90

2. Procurement of Manufacturing Equipment ....................................94

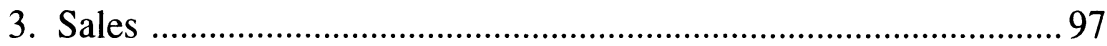

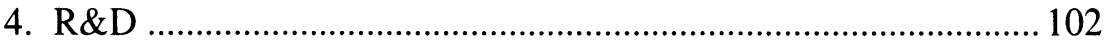

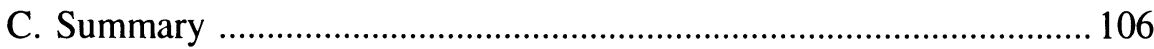

\section{Chapter Four Effects of Cooperation-oriented CCC Interaction in Procurement Relations 113}

A. Procurement of Parts and Materials .................................................. 115

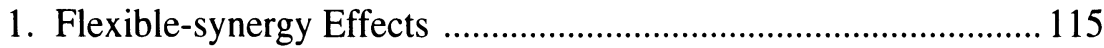

2. Market-like Effects ............................................................................. 122

3. Summary: Dynamics of Cooperation-oriented CCC Interaction .. 128

B. Procurement of Manufacturing Equipment ......................................... 133

1. Flexible-synergy Effects ................................................................. 133 


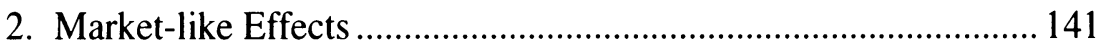

3. Summary: Cooperation-oriented CCC Interaction and Specialization

C. Comparison of CCC Interaction in the Procurement of Parts/Materials and of Equipment

\section{Chapter Five Effects of Competition-oriented CCC Interaction in Sales and Internalized Interaction in R\&D 155}

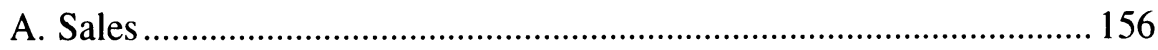

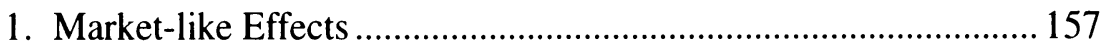

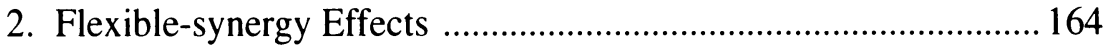

3. Summary: Tough Horizontally-related and Highly Cooperative Intrafirm Customers .................................................................. 168

B. Dynamics of Intrafirm Relations in R\&D ....................................... 172

C. Comparison of CCC Interaction in the Procurement of Parts/Materials and Sales

\section{Chapter Six CCC Dynamics and Structure of Intra- and Interfirm Relations 179}

A. Dynamic Mechanism of Competitive-cum-cooperative Interfirm Relations

B. Overall Structure of Intra- and Interfirm Relations ............................. 184

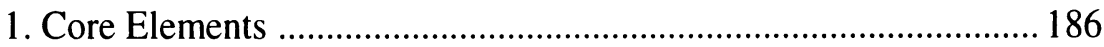

2. Supportive Core Elements .......................................................... 187

3. Semi-peripheral Elements .............................................................. 189

4. Peripheral Elements ......................................................................... 191 
Appendix 193

Bibliography 223

Subject Index 233

Author Index 237 


\section{List of Tables}

Table IN.1 Harmonizing Mechanism for Effectiveness of Cooperation-promoting and Competition-generating Measures

Table IN.2 Top Twelve Japanese Semiconductor Companies for Selected Years

Table 1.1 Types of Governance and Interaction 24

Table 1.2 Difference between Vertical and Horizontal Interaction in Flexible-cooperation-based Long-term Interfirm Relations .... 38

Table 1.3 Flexible-synergy and Market-like Effects by Type of Governance

Table 1.4 Measures Generating Flexible-synergy and Market-like Effects

Table 2.1 Comparison of Technological Levels Between U.S. and Japanese IC Industries at the Beginning of the 1980s

Table 2.2 U.S.-Japan Comparison of 16K-bit DRAM Quality .................76

Table 2.3 Technical Cooperation in Semiconductor Industry ................. 76

Table 2.4 Semiconductor Manufacturers Ranked by World Market Share in 1971 and from 1980 to 1991

Table 2.5 Top Ten Semiconductor Equipment Manufacturers by Sales in Selected Years 
Table 2.6 Relative Japanese and U.S. Semiconductor Technology

Levels in the Late 1980s

Table 3.1 Estimated Percentage of Total Transacted Value by Type of Interaction and Functional Area

Table 3.2 Nature and Characteristics of Interaction in Procurement of Parts and Materials

Table 3.3 Nature and Characteristics of Interaction in Procurement of Manufacturing Equipment

Table 3.4 Nature and Characteristics of Interaction in Sales 100

Table 3.5 Nature and Characteristics of Interaction in R\&D 104

Table 3.6 Overall Characteristics of Interaction 107

Table 3.7 Governance of Interaction in Functional Areas 109

Table 4.1 Flexible-synergy Effects by Type of Interaction in Procurement of Parts and Materials

Table 4.2 Market-like Effects by Type of Interaction in Procurement of Parts and Materials

Table 4.3 Performance by Type of Interaction in Procurement of Parts and Materials

Table 4.4 Flexible-synergy Effects by Type of Interaction in Procurement of Manufacturing Equipment

Table 4.5 Market-like Effects by Type of Interaction in Procurement of Manufacturing Equipment

Table 4.6 Performance by Type of Interaction in Procurement of Manufacturing Equipment

Table 4.7 Comparison of CCC Benefits by Type of Interaction in Procurement of Parts and Materials and of Manufacturing Equipment 
Table 5.1 Market-like Effects by Type of Interaction in Sales 158

Table 5.2 Flexible-synergy Effects by Type of Interaction in Sales ...... 163

Table 5.3 Performance by Type of Interaction in Sales 169

Table 5.4 Performance by Type of Interaction in R\&D 173

Table 5.5 Comparison of CCC Benefits by Type of Interaction in Procurement of Parts and Materials and in Sales

Table 6.1 Overall Structure of Intra- and Interfirm Relations 184

Appendix Table 2.1 Type of Semiconductor 194

Appendix Table 2.2 Technological Development and Rough

Estimates of Time Lags in Selected

Semiconductor Products

Appendix Table 2.3 Selected Semiconductor-industry-related Events in Japan

Appendix Table 2.4 Development of Organizational Goals, Structure, and Strategies for Semiconductor Production in Company A

Appendix Table 2.5 Development of Organizational Goals, Structure, and Strategies for Semiconductor Production in Company B

Appendix Table 5.1 Flexible-synergy and Market-like Effects by Type of Interaction in R\&D 


\section{List of Figures}

Figure IN.1 Cooperation-promoting and Competition-generating Measures in Procurement Relations

Figure 1.1 Harmonizing Mechanisms and Path-dependent Development of Institutions 21

Figure 1.2 Market Competition and Transformation to Long-term and Pseudo-long-term Flexible Cooperation, and Cooperation- and Competition-oriented CCC Interfirm Relations

Figure 2.1 Degrees of Innovativeness: Indicators and Management Strategies

Figure 2.2 Balance of Payments for Patent and Technical Fees in the Semiconductor Division of Company A (1966-1984) ....77

Figure 2.3 Balance of Payments for Patent and Technical Fees in Company B (1980-1985) 78

Figure 2.4 Development of Japanese Semiconductor Industry and Degrees of Innovativeness 83 


\section{Preface}

This book is the cumulative outcome of several projects. My interest in the semiconductor industry started when I was involved in a United Nations University project titled "Japan's Self-reliance in Science and Technology for National Development." The late Professor Toshio Shishido, then the Vice President of the International University of Japan, generously included me in the project as a young scholar along with prominent Japanese specialists in technology and development.

My interest in institutional analysis began when I was invited to be visiting assistant professor at the University of Wisconsin-Madison in 1987. I am grateful to Professor Solomon Levine for providing me with such a rare opportunity. There I met Professor Rogers Hollingsworth, who introduced me to the fascinating field of institutional analysis and to a group of top-level scholars working in the field. Inspired by institutional analysis, I began to develop the conceptual framework needed to identify the institutional dynamics of Japanese high-technology industries. Grants from the International University of Japan (1989) and the Japanese Ministry of Education (1990-1991) enabled my colleagues and me to start the project. My role was to investigate the semiconductor industry; Professors Shinichi Watanabe and Ichiro Inukai of the International University of Japan were to inquire into bio-related industries. They gave me invaluable assistance by teaching me an economist's perspective and enriching my conceptual framework. Later, small grants from the Kajima Foundation (1992) and IBM Japan (1993) enabled me to continue research on the semiconductor industry. Travel grants from the International University of Japan (1993), the Nomura International Foundation (1994), the Murata Science Foundation (1996), and the Japan Foundation (1996) have enabled me to pursue and present this research.

In conducting a survey and interviews, I am deeply indebted to the late Professor Saburo Okita, the former Foreign Minister and President of the International University of Japan, for his human dignity and his sincere un- 
derstanding of young scholars. He opened many doors to facilitate interviews with prominent businessmen and to conduct the company surveys. Also greatly appreciated is the assistance offered by several top-level managers of Japanese semiconductor companies for allowing me to conduct research. Needless to say, I am especially thankful to the twenty-nine managers in the seven semiconductor companies who cooperated with me. Without their patience and expertise, this research would not have been possible.

My conceptualization of competitive-cum-cooperative governance has been advanced through the "Comparison of Capitalist Economies" project organized by Professor Rogers Hollingsworth. My work has benefited from criticism by Professor Richard Whitley of the University of Manchester Business School, who commented on my paper in the capitalist-economies project.

The theory of competitive-cum-cooperative interfirm governance presented in this book is the outcome of the intellectual stimulation that I received from friends, company managers, and many scholars with whom I interacted. Ms. Ellen Jane Hollingsworth, the former Research Director of the Mental Health Research Center, the University of Wisconsin-Madison, and Professor Richard Whitley have given me valuable comments on this manuscript. Fr. Robert Ballon and Ms. Yasuko Hamabata of Sophia University have consistently provided me with valuable assistance when I most needed it: during the Advanced Development Management Program and the last stage of editing this book. I am grateful to Ms. Lisa Schreibersdorf for correcting my English and Mr. David Gear and Mr.Carlos Roberto Salas for assisting me at several stages of completion of this manuscript. Of course, none of them is responsible for the content or for any errors.

I am grateful to the Ministry of Education for providing me with a Grantin-Aid for Publication of Scientific Research Results and to the Japan Society for the Promotion of Science for administering the grant.

My deepest appreciation goes to my family members. My wife, Hideko, and my children, Mika and Erina, have been silently and patiently supporting this book project. They did not complain about many days and long hours of work, even when my work spoiled joyful family plans. Our dog, JJ, often lessened my fatigue by showing her joy and by sleeping at my feet during many late nights. 